NBSIR $81-2334$

\title{
Development of Power System Measurements -- Quarterly Report April 1, 1981 to June 30, 1981
}

U.S. DEPARTMENT OF COMMERCE

National Bureau of Standards

Center for Electronics and Electricai Engineering

Electrosystems Division

Wasnington, DC 20234

Une 1981

Prevared for:

Depariment of Energy

Office of Electric Energy Systems

.. Street \& Pennsyluania Ave., N.W.

$-Q C \longrightarrow$ itop 3344

100 ington, DC 20461

.456

$81-2334$

1981 

NBSIR $81-2334$

SEP 161981

\section{DEVELOPMENT OF POWER SYSTEM}

MEASUREMENTS -- QUARTERLY REPORT

APRIL 1, 1981 TO JUNE 30, 1981

R. E. Hebner, Editor

U.S. DEPARTMENT OF COMMERCE

National Bureau of Standards

Center for Electronics and Electrical Engineering

Electrosystems Division

Washington, DC 20234

June 1981

Prepared for:

Department of Energy

Office of Electric Energy Systems

12th Street \& Pennsylvania Ave., N.W.

Mail Stop 3344

Washington, DC 20461

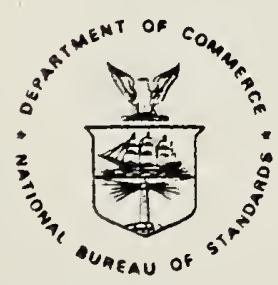

U.S. DEPARTMENT OF COMMERCE, Malcolm Baldrige, Secretary NATIONAL BUREAU OF STANDARDS, Ernest Ambler, Director 



\section{Foreword}

This report is intended to summarize the progress on four technical investigations during the third quarter of FY 1981. Although reasonable efforts have been made to ensure the reliability of the data presented, it must be emphasized that this is an interim report so that further experimentation and analysis may be performed before the conclusions from any of these investigations are formally published. It is therefore possible that some of the observations presented in this report will be modified, expanded, or clarified by our subsequent research. 
TABLE OF CONTENTS

Page

Foreword ............................. ii

Abstract ......................... 1

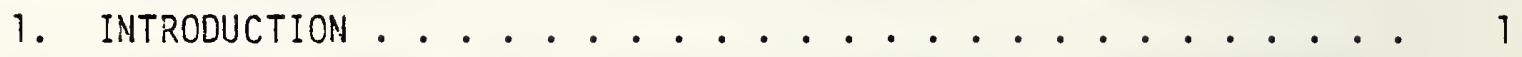

2. DC FIELDS AND ION MEASUREMENTS Project No: AO18-EES ..... 1

3. INCIPIENT FAULT DETECTION/LOCATION Project No: A063-EES . . . 3

4. TECHNICAL ASSISTANCE FOR FUTURE INSULATION SYSTEMS RESEARCH

Project No: A053-EES . . . . . . . . . . . 7

5. OPTICAL MEASUREMENTS FOR INTERFACIAL CONDUCTION AND BREAKDOWN

Project No: A057-EES . . . . . . . . . . 10

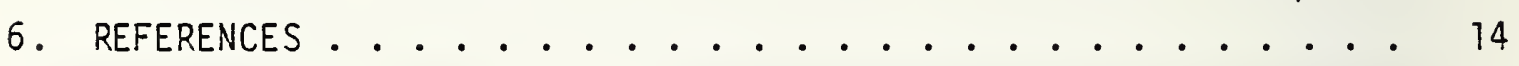


DEVEL OPMENT OF POWER SYSTEM MEASUREMENTS -- QUARTERLY REPORT Apri1 1, 1981 to June 30,1981

\section{R. E. Hebner, Editor}

This report documents the progress on four technical investigations sponsored by the Department of Energy and performed by the Electrosystems Division, the National Bureau of Standards. The work described covers the period April 1, 1981 to June 30, 1981. The report emphasizes measurements of ion density in air, the use of signals above $1 \mathrm{GHz}$ to detect incipient faults in cables, the measurement of the by-products which develop during partial discharge activity in $\mathrm{SF}_{6}$, and the determination of the breakdown behavior of an oil-paper interface.

Key words: cables; composite insulation; dc fields; high voltage; incipient fault; insulation; liquid breakdown; $\mathrm{SF}_{6}$; space charge; transformer $0 i 1$.

\section{INTRODUCTION}

Under an interagency agreement between the U.S. Department of Energy and the National Bureau of Standards, the Electrosystems Division, NBS, has been providing technical support for DOE's research on electric energy systems. This support has been concentrated in four areas -- the measurement of electric fields, the measurement of the electromagnetic properties of solid insulating materials and cables, the measurement of partial discharge ohenomena in gaseous dielectrics, and the measurement of interfacial electrostatic fieid distributions and of soace charge density. The technical progress made during the quarter April 1 to June 30,1981 , is summarized in this report.

\section{DC FIELDS AND ION MEASUREMENTS Project NO. AO18-EES}

The objectives of this effort are to investigate devices and measursment techniques which may be used to characterize the electrical environment near high voltage dc (HVDC) transmission lines, to evaluate methods being used for calibrating such devices, and to develop and establish calibration facilities at NBS which will permit independent verification of the accuracy of user calibrations.

By developing appropriate methods of instrument calibration, it will be possible to compare measurements taken in the vicinity of a high voltage transmission line with measurements taken in biological exposure facilities. Such a comparison will be necessary in any formal or informal risk assessment. 
Most of the effort during the reporting period has been concerned with measuring the efficiency of filtration methods for removing ions from an air stream. Previous measurements $[1,2]$ indicated that the transmission of ions through a high efficiency particulate air (HEPA) or "absolute" filter was no greater than one percent. These measurements were made by measuring the conductivity of air before and after it passed through the filter. By virtue of this high efficiency for removing charge from an air stream, a HEPA filter can be used to determine space charge density by measuring the volumetric flow rate through the filter and the current resulting from the charge collected by the filter.

A somewhat different approach was followed in the present work. A parallel-plate ion counter [3] was used to measure the space charge remaining in the air after it passed through the filter. An air stream containing ions was drawn from a low-speed air flow facility developed to provide a volume space charge [3] and passed through the filter-counter connected in series as shown in figure 1. By comparing the space charge density measured by the two systems, a value for the transmission of ions through the filter was obtained. In this report, the transmission of the absolute filter is defined as the space charge density measured by the counter divided by the sum of the densities measured by the counter and by the filter.

The measurements were made for different electrical conditions and flow rates. Positive and negative ion densities ranged from $5 \times 10^{4}$ to $5 \times 10^{5} / \mathrm{cm}^{3}$ when the air flow facility was used. In a related measurement, an alpha particle source located near the filter inlet produced a nearly neutral net space charge in which there were equal positive and negative ion densities of $9 \times 10^{6} / \mathrm{cm}^{3}$. Flow rates were adjusted so that air velocities at the face of the filter varied from 2 to $5 \mathrm{~m} / \mathrm{s}$.

For all of the experimental conditions examined, the transmission of the filter was less than $4 \times 10^{-3}$. There was large variability observed in the transmission for data runs taken on different days. The largest uncontrollable variable in the present measurements is the air that enters the air flow facility. Both the ion counter and the filter have measurement capabilities which depend on ion mobilities, so that some variability would be expected in the filter transmission if the ion mobility soectra were not kept constant.

The measurements obtained using the filter-ion counter combination are summarized in figure 2. Here a typical spread in observed values for transmission is indicated by an "error" bar. Also shown are the earlier results of ?altridge and of Moore et al.

One way to alter the mobility spectrum of the ions is to insert an absolute filter in the inlet of the air flow facility. ilith this operating condition, the air passing through the source region is iree of particulates and charge. When operatad in this way, the air flow through the system is substantially reduced due to a lack of 
flow capacity in the fan. As a result, signal levels drop to the point where only estimates of the transmission can be made. For these measurements, the transmission was always less than for the unfiltered measurements. These results are not shown on figure 2.

A very low transmission was observed for the situation with low net space charge but high positive and negative ion densities as produced by the alpha particle source. Here only a few values as large as 10-6 were observed, as indicated on figure 2 . All other data points were less than $10^{-6}$ and are not shown.

Measurements of the transmission of other filter materials were made under similar conditions. For these filters, transmissions ranged from 5 to 20 percent. A report describing the experimental procedure and all the measurements summarized above is in preparation. From these measurements, it is clear that the absolute filter can be a useful device for measuring space charge densities with uncertainties of less than 1 percent (ignoring errors due to losses in inlet ducts and flow rate).

Other research activities during the quarter included initial measurements of the effects of operating ion counters above ground in an environment with dc fields and space charge. These measurements were made by using a monopolar line assembled in a high voltage lab. The line was operated to produce vertical current densities comparable to those found under present HVDC transmission lines.

During the next quarter, the ion counter measurements will be continued. Reports describing the filter work and the low soeed air flow facility will be completed.

For further information, contact Dr. R. H. MCKnight, (301) 921-3121.

\section{INCIP IENT FAULT DETECTION/LOCATION Project No: A063-EES}

The objective of this program is to identify and, insofar as practical, remove technical barriers to the develooment of a successful incipient fault detector/locator for underground power transmission use. NBS responsibility includes conducting an experimental program that will aid the development of an incioient fault detection/location system by measuring the rf characteristics of oower cables, and evaluating the frequency content of partial discharge pulses emanating from incipient fault sites in a cable dielectric.

Previous measurements at NBS had indicated that the attenuation of the nigh-frequency components in the apolied voltage pulse limits the resolution. In particular, iaboratory investigation of the attenuation as a function of frequency suggested that the loss occurs primarily in the semiconducting screening layers adjacent to the inner and outer conductors. 


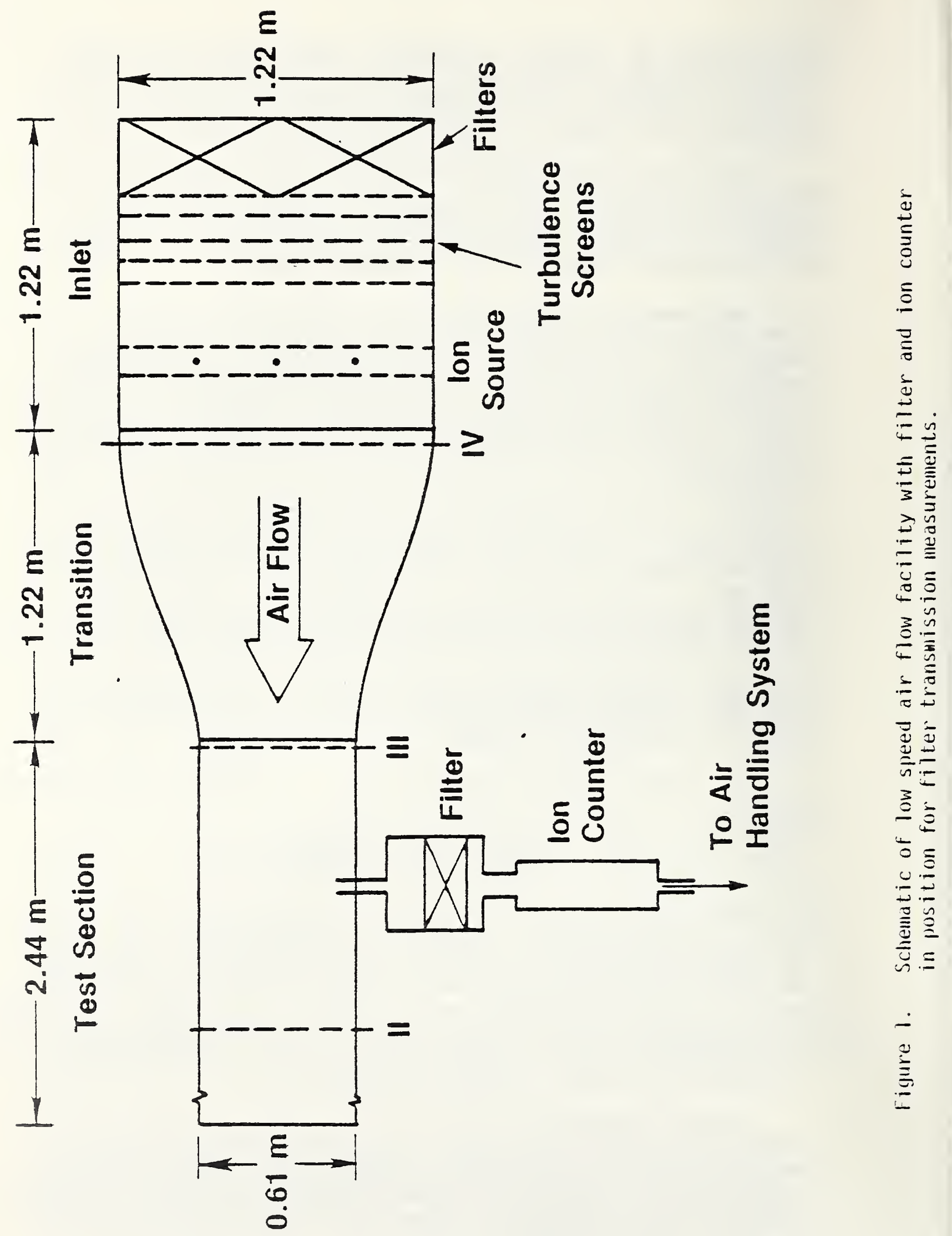




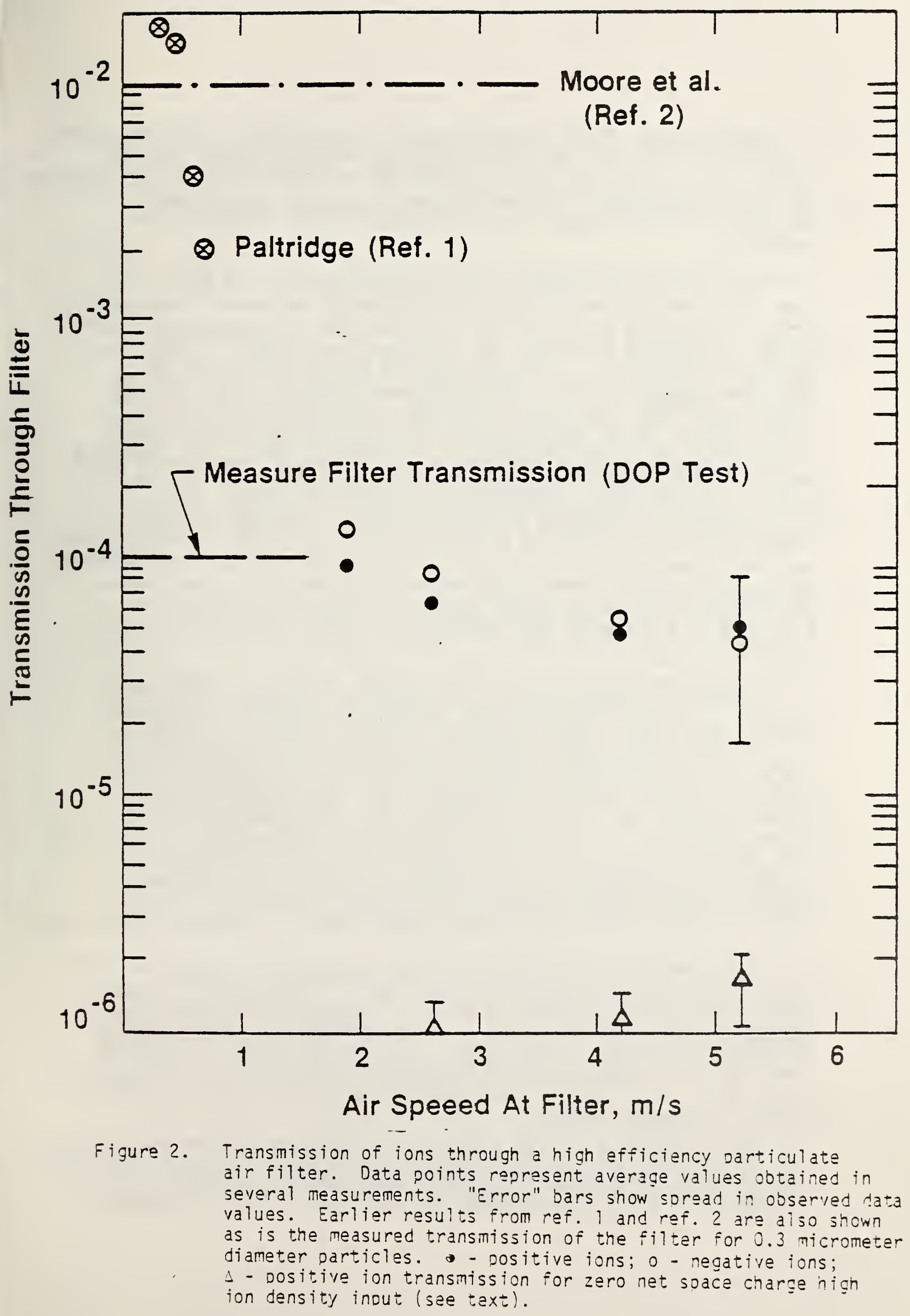


Because most of the losses occurred in the cables' screening layers, it was recognized that another possibility exists. Higher frequency (several GHz) waveguide modes, excited and confined within the polyethylene in a frequency range of minimal attenuation, should be extremely sensitive to the presence of small defects such as "trees" in the dielectric.

Pursuant to this concept, initial measurements were made using time domain reflectometry methods and a special microwave "1auncher" array. The method was'unsuccessful because the high-frequency content in the transmitted pulse and the reflected signal were too small for meaningful detection. A frequency domain method was then tried with some success. Using a microwave sweep generator 12 to $18 \mathrm{GHz}$ range) and a sensitive spectrum analyzer, RF transmission tests were conducted on several power cables. These measurements, though simple, did verify the transmission of microwave energy in a waveguide mode within the cable's dielectric. There were also indications that several modes may have existed and that the launcher and pickup arrays were poorly matched to the dielectric. In order to better understand the coupling mode patterns and the transmission, measurements were performed using simple polyethylene rods to simulate the dielectric (without the center conductor or screening layers) of a power cable. The rods were high-density polyethylene of $4.5 \mathrm{~cm}(1.75 \mathrm{in}$.$) and$ $5.0 \mathrm{~cm}(2 \mathrm{in.})$ diameters and lengths that ranged from about 0.6 to 2.4 meters.

Attenuation measurements as a function of frequency were made on the $4.5 \mathrm{~cm}$ rods using a length substitution method. Preliminary results showed good transmission qualities at frequencies from about 7 to $13 \mathrm{GHz}$. There were, however, near field effects in the ends of the rods which made data interpretation difficult. Employing longer rod lengths, the attenuation apoeared small using what is believed to be TEOl mode and possibly higher modes. These modes are confined to the dielectric such that the electric field vector does not penetrate the outer rod boundary, nor does any field exist near the canter of the rod. This being true, the presence of semiconducting screening layers near the center and outside of cables should have little effect on the propagation and hence should cause a minimum of attenuation.

Measurements are planned to improve the launcher and pickup arrays which couple microwave energy into and out of the cable while also providing good high voltage isolation. Attenuation measurements will continue on the dielectric rods. As the measurement techniques are perfected, the rods will be changed, one step at a time, to simulate power cables by adding a center conductor, screening layers, and, finally, outer skid wires. The next and immediate goal is to design and test several microwave couplers.

Our paper entitled "The Detection of Incipient Faults in Transmission Cables Using Time Domain Reflectometry Techniques," has been accepted for publication and will be presented at the 8th IEEE/PES Conference and 
Exposition on Overhead and Underground Transmission and Distribution to be held in Minneapolis, September 1981.

For further information, contact Dr. W. E. Anderson, (301) 921-2131.

\section{TECHNICAL ASSISTANCE FOR FUTURE INSULATION SYSTEMS RESEARCH Project NO: A053-EES}

The objective of this project is to develop diagnostic techniques to monitor, identify, and predict degradation in future compressed gas electrical insulating systems under normal operating conditions. Focus is on the fundamental information and data needed to imorove test design and performance evaluation criteria. The investigation of partial discharges (corona) in gaseous dielectrics is emphasized. This phenomenon gives rise to degradation of the gas under high electrical stress and may lead to breakdown. Measurement of partial discharge inception in highly nonuniform fields may also prove to be a preferred method to determine dielectric strength of electronegative gases.

Planned activities for FY-81 include: (1) estimate the sensitivity of low-frequency dielectric constant measurements as a monitor of polar molecules in $\mathrm{SF}_{6} ;(2)$ determine effects of trace amounts of $\mathrm{H}_{2} \mathrm{O}$ and other polar gas molecules on partial discharge behavior in SFG; (3) prepare an archival publication on pulse characteristics of positive and negative dc corona in SFG; (4) examine the effect of radiation on electron avalanche development and measure the radiation emitted by corona; (5) identify gaseous decomposition products resulting from corona in mixtures of SF 6 , and determine the rate of buildup of oxyfluorides as a function of discharge power; (5) model discharge inception and test these models in a controlled-ionizationzone test cell (in collaboration with MIT); and (7) initiate a program to evaluate electrical breakdown data for gases (in collaboration with NBS-JILA). In addition, there was an incomolete investigation in FY-80, namely, the measurement of laser-induced optogalvanic signals in electric discharges of rare gas- $F_{6} 6$ mixtures to determine the effectiveness of $S_{6} 6$ in quenching metastable soecies.

Progress was made during the reporting quarter on all activities except (1) and (3) which are comoleted and (2) which is nearly complete. The major effort, however, has been focused on activity (5). Also advances were made both at NBS and MIT toward the accomolishment of activity $(6)$. New technical information acquired as a result of these two activities is highlighted in this report.

The rates of production of the by-products generated in a corona discharge were neasured for SF 6 at an absolute pressure of $200 \mathrm{kPa}$ ( 2 $\mathrm{atm}$ ) for average discharge power levels in the range of 50 to $670 \mathrm{mw}$ with polished point-plane electrodes. The volume of the test call was 4.0 liters and the corona was operated at constant 
current for a positive dc-voltage applied to the plane electrode. The currents used were within the range of 1.5 to $16.0 \mu \mathrm{A}$. A gas chromatograph-mass spectrometer (GC/MS), details of which have previously been discussed [4], was used to monitor the concentrations of $\mathrm{H}_{2} \mathrm{O}$, $\mathrm{SOF}_{2}$ (thionylfluoride) and $\mathrm{SO}_{2} \mathrm{~F}_{2}$ (sulfurylfiuoride) as a function of time. The concentrations of the latter two compounds could be determined quantitatively with a sensitivity of about 1 pom. To assure reliability in the quantitative analysis, the GC/MS was calibrated before and after each corona degradation experiment using several individually prepared standard samples of $\mathrm{SOF}_{2}$ and $\mathrm{SO}_{2} \mathrm{~F}_{2}$ in SF 6 .

Only relative concentrations, however, of $\mathrm{H}_{2} \mathrm{O}$ could be determined with the present system. It is believed that $\mathrm{H}_{2} \mathrm{O}$ is produced by discharge-induced desorption from the electrode surface. Its concentration builds up rapidly with time at first and then levels off, reaching roughly a constant value independent of discharge power. It has been hypothesized [4-7] that SOF2 results primarily from hydrolysis of the primary decomposition product $S_{4}$, whereas, $\mathrm{SO}_{2} \mathrm{~F}_{2}$ is generated within the discharge via reactions of sulfurfiuorides with free oxygen and $\mathrm{H}_{2} \mathrm{O}$. The species $\mathrm{SO}_{2} \mathrm{~F}_{2}$ has been observed [7] to be absent after arc discharges have occurred in $\mathrm{SF}_{6}$.

The results of our measurements of $\mathrm{SOF}_{2}$ and $\mathrm{SO}_{2} \mathrm{r}_{2}$ concentrations as a function of the net energy dissipated for three different power levels are shown in figure 3 . The significant conclusions from these results are: a) the production rates of $\mathrm{SOF}_{2}$ and $\mathrm{SO}_{2} \mathrm{~F}_{2}$ are constant, at least up to concentrations of $200 \mathrm{ppm}$, and directly proportional to the power dissipated, and b) $\mathrm{SOF}_{2}$ and $\mathrm{SO}_{2} \mathrm{~F}_{2}$ aopear with nearly equal concentrations. The fact that $\mathrm{SO}_{2} \mathrm{~F}_{2}$ is produced with much more relative abundance in a corona discharge than in an arc is interesting, and possible reasons for this important observation need to be explored.

In the area of theoretical modeling of corona discharge phenomena, computer codes were written that allow calculation of average electron avalanche size, negative corona inception voltages based on the streamer criterion, and the active electron initiation volumes for positive corona in SFg. The calculated negative corona inceptions agree favorably with our previously reported measurements $[4,8]$, although the basis for this agreement needs further examination. An example of results obtained from calculation of electron initiation volumes is shown in figure 4 . Shown in the figure are the hyperbolidal point electrode (shaded area) and the boundaries of the volumes at the indicated voltages from which electrons, once released, can produce avalanches in excess of $1 \times 10^{8}$ electrons sufficient to satisfy the streamer critarion. Assuming uniformity of initiating electron production, the probability of occurrence of avalanches greater than 108 electrons is directly proportional to this volume. The calculation of these volumes can be used to help exolain the previously observed [8] polarity effect in $S_{6} 6$ corona inceptions and is an important first step 


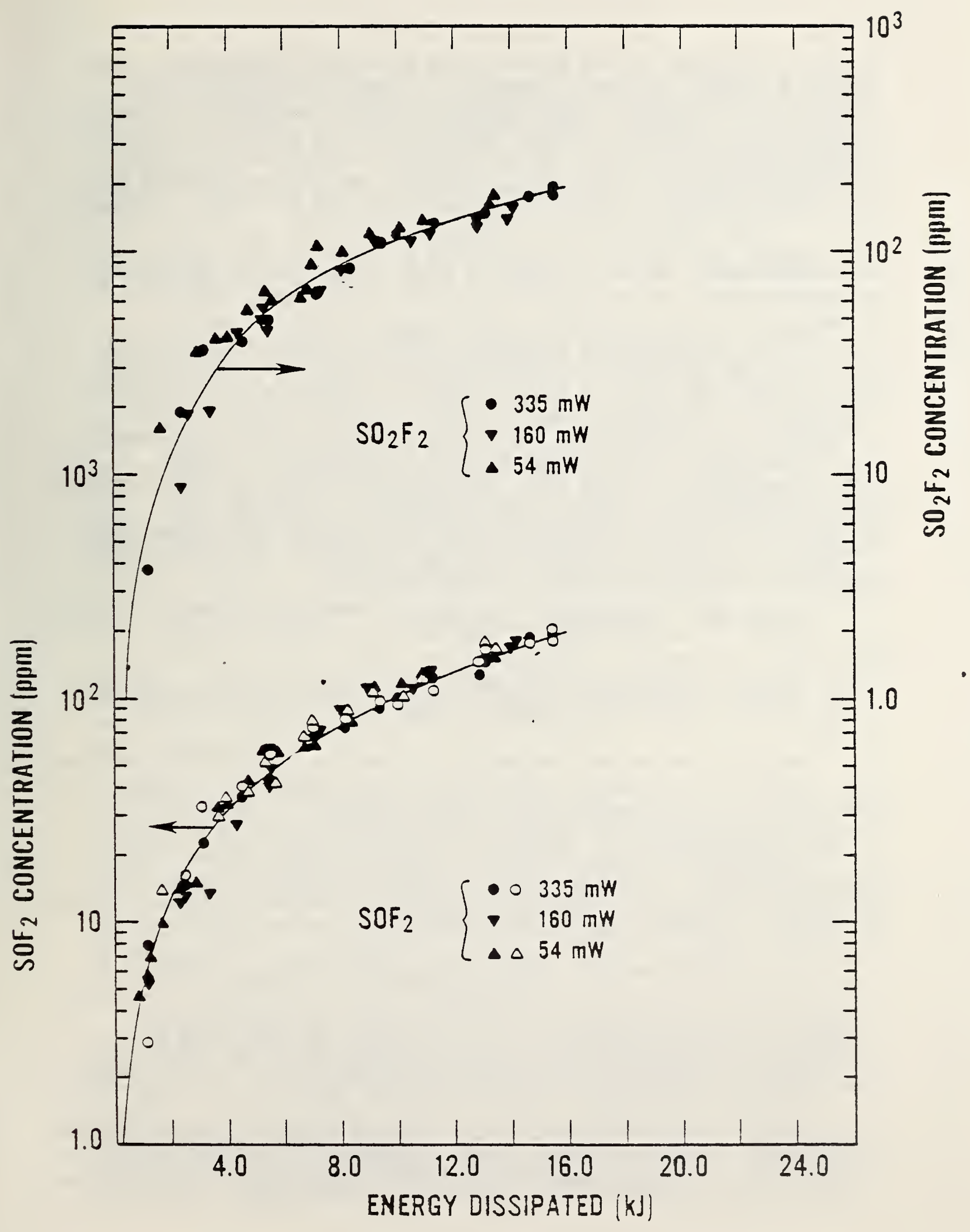

Figure 3. Measured concentrations of $\mathrm{SCF}_{2}$ and $\mathrm{SO}_{2} \bar{F}_{2}$ as a function of net energy dissipated in corona discharges ooerated at the indicatad Dower levels. 
in the calculation of the electron avalanche size distributions for positive corona. A direct comparison of these distributions with results of our previous measurements [6] should be possible. The results of our modeling effort together with our results of corona inception measurements are being prepared for publication in the IEEE Transactions on Electrical Insulation and for presentation at the 1981 Conference on Electrical Insulation and Dielectric Phenomena.

During the next quarter we intend to complete the archival paper mentioned above, and also prepare a paper on our corona degradation measurements for presentation at the 3rd International Symposium on Gaseous Dielectrics. Further work will be carried out on the measurement of by-product production rates in corona (activity (5)) and extension of these measurements to gas mixtures. Measurements will be performed using a tunable laser to determine the wavelength dependence of photon enhanced avalanche initiation for positive discharges in SF6 (activity (4)). The purpose of these measurements is to understand the basic mechanisms of discharge initiation. Improvements will also be made in the sensitivity of our pulse height analysis technique so that our measurements of avalanche size distributions can be extended to the region of greatest theoretical interest. Investigations will continue on methods for improving the quantitative analysis of $\mathrm{H}_{2} \mathrm{O}$ in compressed $\mathrm{SF}_{6}$.

For further information, contact Dr. R. J. Van Brunt (301) 921-3121.

5. OPTICAL MEASUREMENTS FOR INTERFACIAL CONDUCTION AND BREAKDOWN Project No: A057-EES

The objective of this project is to develop techniques to measure the interfacial phenomena which influence the electrical breakdown characteristics of composite insulation systems. In particular, the role of space charge in electrical breakdown is being investigated. In transfomer oils, the electro-optic Kerr effect is being used to observe electric fields as a means of detecting space charge. This study concentrates on oil-paper (pressboard) systems in which the solid insulator is either parallel or perpendicular to the electric field.

It is recognized that imourities and possibly soace charge have an influence on the failure of composite insulating systems. Possible formation of space charge is monitored as the concentration and composition of impurities is varied. In addition, the breakdown strength is measured and the locations of breakdowns are observed in the composite insulation system with impurities.

Investigations described in the previous quarterly report provided evidence of significant space charge distortion in contaminated transformer $0 i 1$ at elevated temperatures. The contaminated oil was obtained 
from a transformer which had failed. During this quarter, a system was designed and constructed to extend this investigation to $100^{\circ} \mathrm{C}$ and above. The nylon and polyethylene parts used with the laminated phenolic cell were found to be unsuitable for use at these elevated temperatures. The cell's plumbing system had to be refurbished using brass fittings and screws, fluorocarbon tubing, and some acetal plastic parts. At the end of the quarter, the changes were completed and the cell was tested to withstand $100^{\circ} \mathrm{C}$ for several hours. It is anticipated that the results of the study at higher temperatures will be available in the next quarterly report.

While the system to measure space charge in oil at elevated temperatures was constructed, experiments were conducted to investigate the location of breakdowns in an oil-paper system containing contaminated oil. Previous NBS studies have shown that for a clean, well characterized system, breakdown does not necessarily occur at an oil-paper interface and that the presence of an interface does not necessarily reduce the breakdown strength of a system [10]. The previous investigation raised practical as well as fundamental questions. Field experience and some previous experiments by NBS and others had demonstrated that interfacial breakdowns at relatively low voltages were a problem. Since interfacial breakdown was unlikely in clean, carefully prepared systems, a possibility that impurities contribute to the lowered breakdown voltage was investigated. The type of experiments documented in reference 10 were repeated in expanded form by investigating both clean, well-controlled systems and contaminated systems. The breakdown strength was measured and the location of breakdowns observed in a "clean" system, in a system in which the oil was contaminated, and, indirectly, in a system in which the paper was contaminated.

Obtaining statistically significant data is a very time consuming process as the breakdown typically destroys the interface. The apparatus, therefore, must be disassembled and reassembled between "shots." To minimize the amount of time expended, it was felt preferable to survey the breakdowns at a number of selected conditions with relatively few "shots" rather than applying numerous "shots" at any one condition. In spite of that, more than 150 breakdowns had to be performed to observe any preliminary trend. The results of the preliminary survey are reported here.

To determine the influence of oil purity on breakdown location, measurments were performed using clean (mechanically filtered and degassed) $0 i 1$ and $0 i 1$ which was removed from a transformer which had failed. The electrodes were two discs with rounded edges which provided a uniform field. The discs were split along a diameter to clamp the paper sample parallel to the electric field. The applied voltage was $60-i z$ ac, ramped at a rate of about $3 \mathrm{kV} / \mathrm{s}$. The data obtained for measurements in clean oil are summarized in table 1. 
Table 1. Data taken using clean oil.

Condition

No Interface

Interface Present

Interface Present but Breakdown not at Interface

Interface Present and 3 reakdown at Interface
Number of Breakdowns Recorded 15 10
Breakdown Voltage $(2.5 \mathrm{~mm}$ gao)

$76 \pm 10 \mathrm{kV}$

$68 \pm 11 \mathrm{kV}$

$74=7 \mathrm{kV}$

$56=9 x y$

The results for the contaminated oil are shown in figure 5 . It was determined that the contaminated oil contained small oarticles which could be precipitated by gravity and which presumably influenced breakdown. The first five shots were taken with no interface in the system. The system had, however, been shaken to suspend the fine particles which had drifted to the bottom of the reservoir. In this case, the breakdown voltage was $53 \pm 7 \mathrm{kV}$--significantly be Tow the $76=10 \mathrm{kV}$ recorded for clean 011 .

The second five neasurements with were taken with an interface in place had a higher breakdown voltage, $65=12 \mathrm{kV}$. Suspecting that the suspended particles were dominating the breakdown behavior, the system was permitted to sit undisturbed overnight. Following this extended sattling time, five breakdowns were recorded without an interface. The average breakdown yoltage was $74 \pm 7 \mathrm{kV}$--about the same as clean $0 i 7$. A series of tan shots was then taken, five with an interface and five without, with the system shaken to distribute the particles throughout the interelectrode region. Without an interface, the average breakdown voltage was $34 \pm 5 \mathrm{kV}$ and with an interface $39=8 \mathrm{kV}$. From this set of data, it was postulated that although the oil contamination (esoecially particulate contamination) influences the breakdown voltage of the system, it has little effect on the interfacial phenomena because again the breakdown does not necessarily occur at the interface even with dirty $0 i 1$.

The effect on braakdown arising from the condition of the paper was obtained indirectly. Approximately 100 breakdowns are not reported in table 1 or in figure 5. These occurred at relatively low voltages, whenever an interface was included, and their cause was traced to the condition of the paper. The impregnating procedure similar to the one used in manufacture of electrical equioment was unsatisfactory for this application. A new procedure, whereby the paper was impregnated with oil before installation in the breakdown call and 


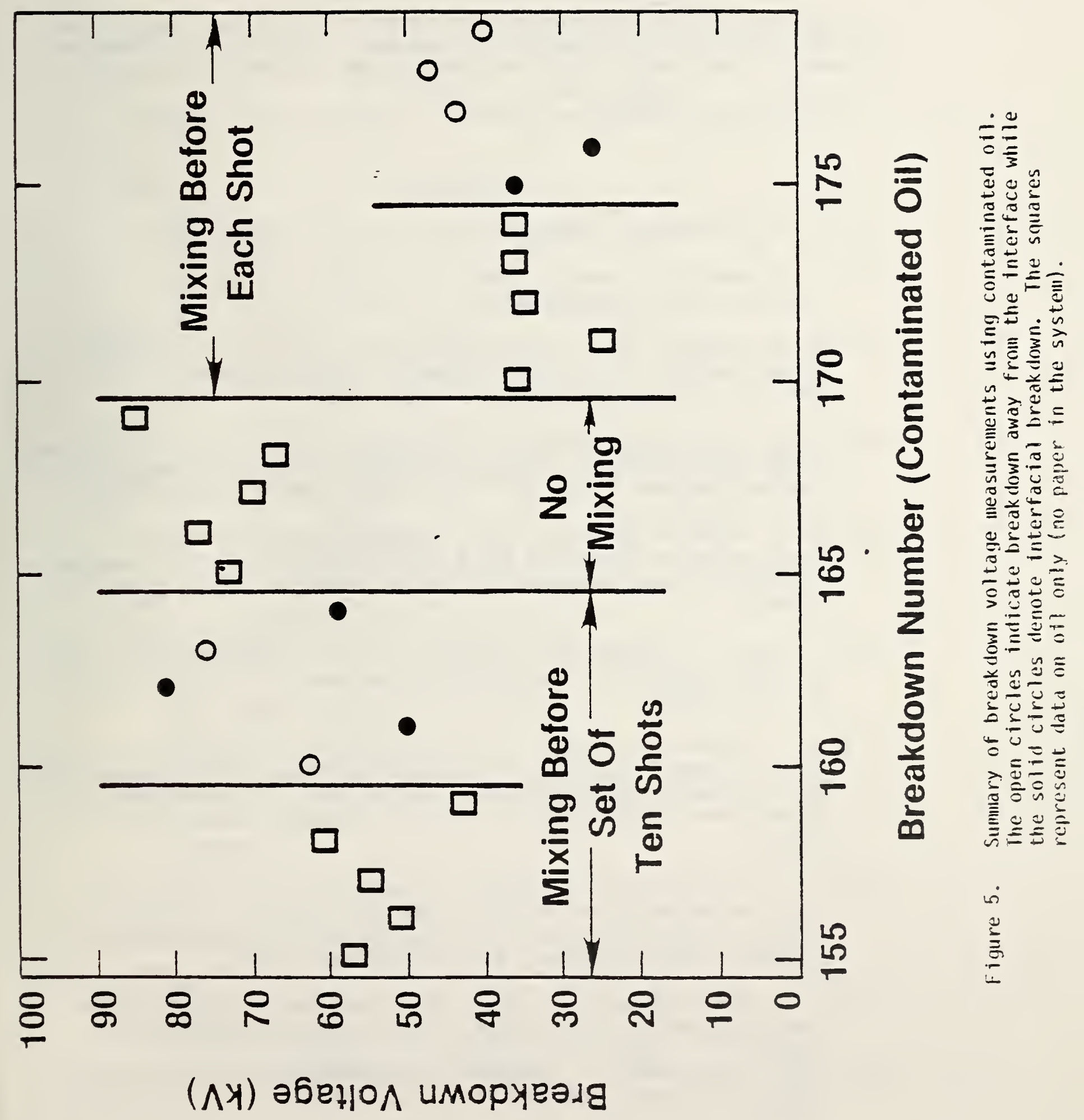


the cell was filled with oil in the presence of dry nitrogen rather than vacuum, was found to be satisfactory.

The results obtained during this quarter point to the paper as the critical element in the interfacial breakdowns. Efforts are continuing to quantify the effects of air and water on the interfacial breakdown.

For further information, contact E. F. Kelley (301) 921-3121.

\section{REFERENCES}

[1] G.W. Paltridge, J. Geophys. Res. Vol. 72, p. 1269 (1966).

[2] C. B. Moore, B. Vonnegut, and F. J. Mallahan; J. Geophys. Res. Vol. 66, p. $3219(1961)$.

[3] R. H. Mcknight, F. R. Kotter, M. Misakian, and P. Ortiz, "1980 Annual Report: Electric and Magnetic Field Measurements," Nat. Bur. Stand. (U.S.) NBSIR $81-2267$ (1981).

[4] R. J. Van Brunt, M. Misakian, D. A. Leep, K. J. Moy, and E. C. Beaty, "1980 Annual Report: Technical Assistance for Future Insulation Systems Research," Nat. Bur. Stand. (U.S.) NBSIR $81-2242$ (1981).

[5] R. J: Van Brunt and D. A. Leep, "Partial D ischarge Induced Degradation of Compressed SF 6 ," Proc. Norkshop on Arc By-P roducts in Gas-Insulated Equipment, EPRI Final Report $3-80-8-L D$, pp. 13-14 (1980).

[6] A. Baker, R. Dethlefsen, J. Dodds, N. Oswalt, and P. Vouros, "Study of Arc By-Products in Gas-Insulated Equipment," EPRI Final Report, El -1646 (1980).

[7] C. C. Boudene, J. Cluet, G. Keib, and G. Wind, "Identification and Study of Some Properties of Compounds Resulting From the Decomposition of SF 6 Under the Effect of Electrical Arcing in Circuit-Brakers," Revue Generale De L'Electricite (RGE) - Numero Special, pp. 45-78 (1974).

[8] R. J. Yan Brunt and M. Misakian, "Comoarison of $\mathrm{OC}$ and $60 \mathrm{~Hz} A C$ Positive and Negative Partial Discharge Inceptions in SF6, "Proc. Conf. on Electrical Insulation and Dielectric Phenomena, National Academy Press, Washington, D.C., pp. $461-469$ (1980).

[9] R. J. Van Brunt and D. A. Leep, "Characterization of Point-P lane Corona Pulses in SF6," J. Appl. Phys. (to be published, 1981).

[10] E. F. Kelley and R. E. Hebner, "Breakdown Betiveen 3are Electrodes With an 017 -Paper Interface," Nat. Bur. Stand. (U.S.) NBSIR 80-2071 (1980). 


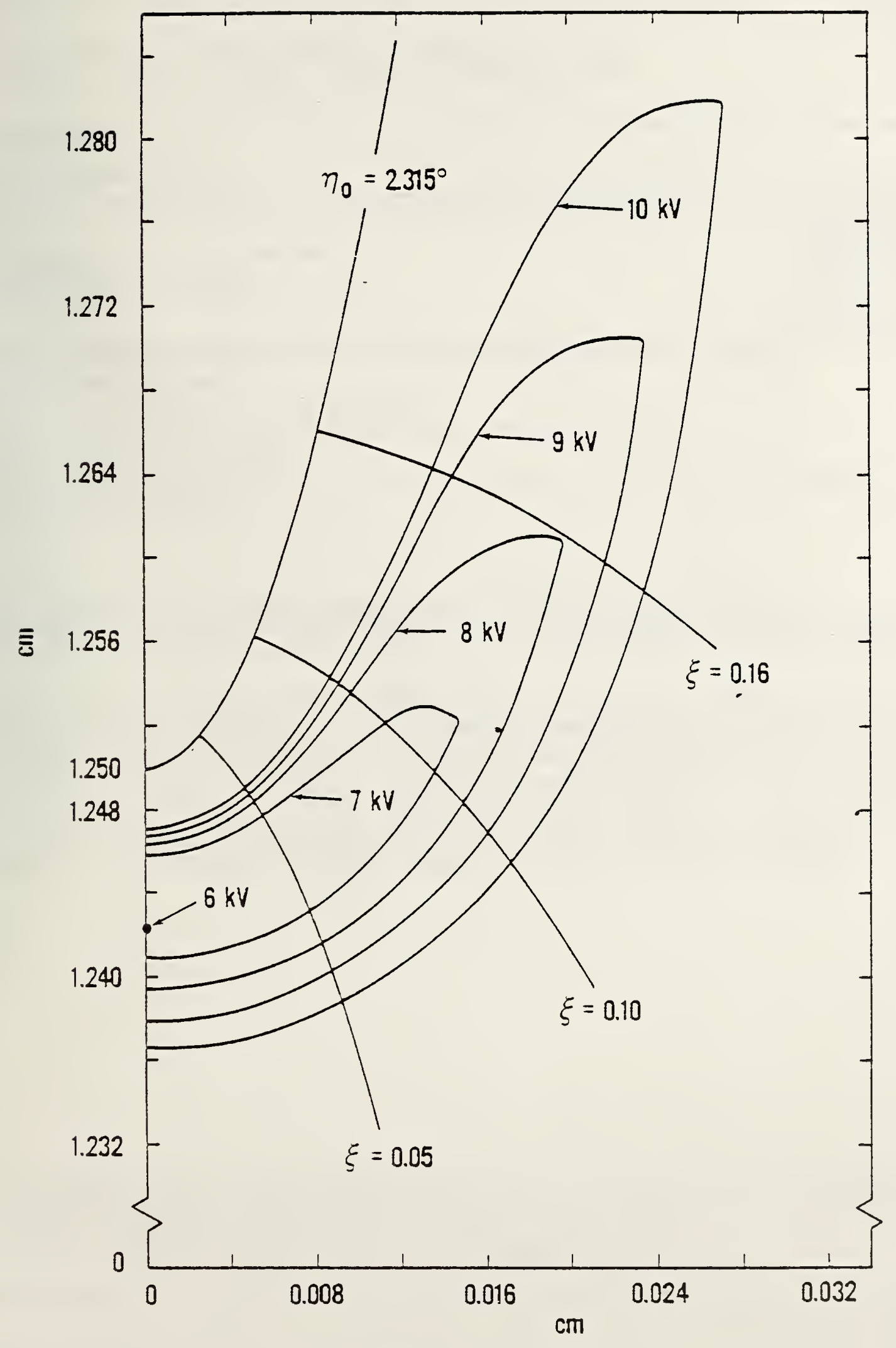

Figure 4. Calculated boundaries of discharge initiation volumes at the indicated voltages for positive corona in SFo at

$100 \mathrm{kPa}$. Only electrons oroduced within these boundaries

can give rise to electron avalanches in excess of $1 \times 10^{8}$ electrons. 

NBS-114A (REV. 2-8C)

U.S. DEPT. OF COMM.

1. PUBLICATION OR

REPORT NO.

BIBLIOGRAPHIC DATA

SHEET (See instructions)

NBSIR $81-2334$

2. Performing Organ. Report Nof 3. Publication Date

August 1981

4. TITLE AND SUBTITLE

Development of Power System Measurements --

Quarterly Report Apri1 1, 1981 to June 30, 1981

5. AUTHOR(S)

R. E. Hebner, Editor

6. PERFORMING ORGANIZATION (If joint or other than NBS, see instructions)

NATIONAL BUREAU OF STANDARDS

DEPARTMENT OF COMMERCE

WASHINGTON, D.C. 20234

9. SPONSORING ORGANIZATION NAME AND COMPLETE ADDRESS (Street, City, Stote, ZIP)

7. Contract/Grant No

Interagency Agreement

EA-77-A-01-6010

Department of Energy

Office of Electric Energy Systems

12 th Street \& Pennsylvania Ave., N.W., Mail Stop 3344

Washington, D.C. 20461

10. SUPPLEMENTARY NOTES

$\square$ Document describes a computer program; SF-185, FIPS Software Summary, is attached.

11. ABSTRACT (A 200-word or less factual summary of most significant information. If document includes a significant bibliography or literature survey. mention it here)

This report documents the progress on four technical investigations sponsored by the Department of Energy and performed by the Electrosystems Division, the National Bureau of Standards. The work described covers the period April 1, 1981 to June 30, 1981. The report emphasizes measurements of ion density in air, the use of signals above $1 \mathrm{GHz}$ to detect incipient faults in cables, the measurement of the by-products which develop during partial discharge activity in $\mathrm{SF}_{6}$, and the determination of the breakdown behavior of an oil-paper interface.

12. KEY WORDS (Six to twelve entries; alphabetical order; capitalize only proper names; and separate key words by semicolons) cables; composite insulation; dc fields; high voltage; incipient fault; insulation; liquid breakdown; $\mathrm{SF}_{6}$; space charge; transformer oil.

13. AVAILABILITY

成 Unlimited

For Official Distribution. Do Not Release to NTIS

Order From Suderintendent of Documents, U.S. Government Printing Office, Washington, D.C. 20402.

Order From National Technical Information Service (NTIS), Soringfield, VA. 2216I
14. NO. OF

PRINTED PAGES

15. Price 


